\title{
Comparison of Bactec NR-660 and Signal systems
}

\author{
KAREN RIMMER, MARGARET CABOT Department of Medical Microbiology, Royal Liverpool \\ Hospital, Liverpool
}

SUMMARY Bactec NR-660, a computerised blood culture system using infrared analysis of microbial generated carbon dioxide, was compared with the Signal system, which detects gaseous pressure (due to bacterial metabolism) by a manometer. Four trials were undertaken: an in vitro evaluation of 99 bacteria in simulated blood cultures, and three prospective comparisons of a total of 2588 paired patient samples.

Combined results for bacteria in simulated blood cultures showed a highly significant difference ( $p$ $<0.001)$ between Bactec NR-660 aerobic medium (6A) and any other phial under test. Detection rates for most bacteria by Signal were on average three times slower than the first Bactec phial (mean delay $58 \cdot 3$ hours).

Overall, the systems were not comparable.

Bactec NR-660 (Johnston Laboratories, Baltimore, Maryland) an automated blood culture system that detects microbial generated carbon dioxide in separate aerobic and anaerobic phials by infrared spectroscopy, was compared with Signal (Oxoid Ltd, Basingstoke, Hampshire), a single phial system that detects gaseous pressure by simple manometry. Due to continual protocol changes recommended by Oxoid Ltd, Signal was compared with Bactec as follows:

(i) An in vitro evaluation of 99 bacteria in simulated blood cultures (trial 1).

(ii) A prospective comparison of 2000 paired patient samples (trial 2).

(iii) A prospective comparison of 433 paired patient samples (trial 3).

(iv) A prospective comparison of 155 paired patient samples (trial 4).

\section{Material and methods}

During trials 1 and 2, Signal media were provided in total head space gas evacuated bottles, and once inoculated, were shaken twice a day for 72 hours and once a day thereafter to day 7 .

In trial 3 Signal media were provided in partially evacuated bottles, and once inoculated, were shaken continuously for 24 hours and then once a day thereafter. The manometer had also been increased in volume from $10 \mathrm{ml}$ to $30 \mathrm{ml}$.

Trial 4 used Signal media that had been modified to reduce the number of false positive cultures.

Throughout the course of the four investigations, the formulation of both Bactec NR-6A (aerobic) and Bactec NR-7A (anaerobic) media remained constant.
Simulated blood cultures were prepared using isolates from septicaemic episodes and were inoculated at 10 colony forming units $(\mathrm{cfu}) / \mathrm{ml}$ or less to each phial and supplemented with $10 \% \mathrm{v} / \mathrm{v}$ of sterile defibrinated horse blood. Manometers were fitted to Signal phials immediately after inoculation. All phials were incubated for a minimum of eight hours and then examined at regular intervals to determine the mean time to detection of positive cultures. All positive findings were confirmed by microscopy and culture.

Patient samples were tested according to laboratory testing schedules, ${ }^{1}$ manometers being fitted to Signal phials on arrival at the laboratory.

\section{Results}

TRIAL 1 (SIMULATED BLOOD CULTURES)

Mean time to detection (in hours) for major bacterial groups is summarised in table 1 . Isolation times for most of the 49 Gram positive bacteria were much improved in Bactec NR-6A compared with Bactec NR-7A or Signal, and showed a highly significant difference $(\mathrm{p}<0.001)$ using a paired $t$ test. ${ }^{2}$ The delay in mean detection time from Signal was more than 30 hours for staphylococci, more than 22 hours for streptococci, and 119 hours for yeasts when compared with results by Bactec NR-6A. This may have been due to the poor aeration of both Bactec NR-7A and Signal phials as there was little or no agitation.

Similar disparity was shown for 50 Gram negative bacteria when Bactec NR-6A was compared with Signal ( $<<0.001)$. Mean detection time in Signal was delayed by 61 hours for fastidious aerobes, $55 \cdot 5$ hours for pseudomonads, and 120.5 hours for miscellaneous 
Table 1 Mean time to detection for major bacterial groups

\begin{tabular}{|c|c|c|c|c|}
\hline \multirow[b]{2}{*}{ Bacteria } & \multirow{2}{*}{$\begin{array}{l}\text { No of } \\
\text { strains }\end{array}$} & \multicolumn{3}{|c|}{ Mean time (hours) } \\
\hline & & $N R-6 A$ & $N R-7 A$ & Signal \\
\hline $\begin{array}{l}\text { Staphylococci } \\
\text { Enterobacteriaceae } \\
\text { Streptococci } \\
\text { Fastidious aerobes } \\
\text { Anaerobes } \\
\text { Pseudomonads } \\
\text { Miscellaneous Gram } \\
\text { negative bacilli }\end{array}$ & $\begin{array}{r}26 \\
25 \\
15 \\
12 \\
8 \\
6 \\
4\end{array}$ & $\begin{array}{l}16 \cdot 1 \\
14 \cdot 2 \\
22 \cdot 6 \\
25 \cdot 1 \\
20 \cdot 8^{*} \\
57 \cdot 2 \\
38 \cdot 5\end{array}$ & $\begin{array}{l}36 \cdot 3 \\
17 \cdot 6 \\
40 \cdot 4 \\
38 \cdot 4 \\
65 \cdot 6 \\
106 \\
\text { No growth }\end{array}$ & $\begin{array}{r}47 \cdot 4 \\
19 \cdot 5 \\
45 \cdot 4 \\
86 \cdot 1 \\
71 \cdot 7 \\
112 \cdot 7 \\
159\end{array}$ \\
\hline $\begin{array}{l}\text { Yeasts } \\
\text { Total }\end{array}$ & $\begin{array}{r}3 \\
99\end{array}$ & $\begin{array}{l}40 \cdot 0 \\
29 \cdot 3\end{array}$ & $\begin{array}{r}135 \cdot 5 \\
62 \cdot 8\end{array}$ & $\begin{array}{l}159 \\
87.6\end{array}$ \\
\hline
\end{tabular}

*Aerotolerant species isolated

Gram negative bacilli. Again this was probably due to poor aeration, resulting in a reduced Eh value maintained when phials remained static. No significant difference $(p>0.3)$ was shown between Bactec NR$7 \mathrm{~A}$ and Signal.

For all bacteria studied, a highly significant difference was shown between Bactec NR-6A and all other phials tested $(p<0.001$ ), but no significant difference between Bactec NR-7A and Signal ( $p>0.5$ ) was established. On no occasion did terminal subcultures yield bacteria which had failed to initiate a positive response.

Total numbers of positive blood culture sets and isolates detected by each system are shown in table 2 .

TRIAL 2 (2000 PAIRED PATIENT SAMPLES)

Analysis of the total number of bacteria isolated in vivo by both systems showed that Signal failed to isolate 35 of $189(18.5 \%)$ Gram positive, 36 of 100 $(36 \%)$ Gram negative, but only one of $12(8.3 \%)$ anaerobic bacteria. Bactec failed to isolate five of 189 $(2.6 \%)$ Gram positive, nine of $100(9 \%)$ Gram negative, and six of $12(50 \%)$ anaerobic bacteria.

Signal detected the presence of micro-organisms before Bactec on the following occasions: 12 of 189 $(6.3 \%)$ Gram positive, 12 of $100(12 \%)$ Gram negative, and eight of $12(66.6 \%)$ anaerobic bacteria. Bactec detected the presence of micro-organisms before Signal on the following occasions: 132 of 189 $(69.8 \%)$ Gram positive, 56 of $100(56 \%)$ Gram negative, and only one of $12(8.3 \%)$ anaerobic bacteria. Equivalence was found in $23.8 \%$ of Gram positive, $32 \%$ of Gram negative, and $25 \%$ of anaerobic bacteria.

Speed of detection by specific laboratory schedule is shown in table 3 . At 24 hours' incubation $74.1 \%$ of positive results were detected by Bactec NR-660 and $51.5 \%$ by Signal. Of the 45 polymicrobic isolations (two or more bacteria present), $95 \%$ of the bacteria were detected by Bactec NR-660 and $76 \%$ by Signal. Highly significant $(p<0.001)$ differences $($ McNemar analysis) ${ }^{s}$ were found between the two systems for both absolute numbers of bacteria recovered and speed of isolation.

Overall contamination of the two systems (isolation of either coagulase negative staphylococci or coryneforms from only one of the phials under test) remained low, Bactec NR-660 yielding $1.7 \%$ and Signal $1 \cdot 2 \%$.

Numbers of false positive results highlighted in the Bactec NR-660 system by potential positive growth values and in the Signal system by a rise in the level of the blood-broth mixture in the manometer were also evaluated: Bactec NR-6A (1.7\%), Bactec NR-7A $(2 \cdot 25 \%)$, and Signal (0.75\%).

On three separate occasions Signal gave false negative culture results when manometer levels, microscopy, and Bactec phials were positive. The isolates missed were Streptococcus pneumoniae, Enterobacter cloacae, and a mixed growth of Staphylococcus aureus and Streptococcus pneumoniae.

\section{TRIAL 3 (433 PAIRED PATIENT SAMPLES)}

A range of bacteria similar to those found in trial 2 were isolated, but there was, however, a difference in the speed of detection within the first 24 hours. Bactec detected $75 \%$ of all bacteria and Signal $63 \cdot 2 \%$ of all isolates. Presumably, this was due to the improved aeration which continuous shaking for 24 hours provides.

Contamination rates for both systems remained at less than $1.0 \%$, but there was a significant increase in the number of false positive results highlighted by Signal $(11 \cdot 3 \%)$, Bactec NR-6A $(1 \cdot 1 \%)$, and Bactec NR-7A $(2 \cdot 1 \%)$. This would suggest that while aeration improves isolation rates it has a detrimental effect on false positive rates.

\section{TRIAL 4 (155 PAIRED PATIENT SAMPLES)}

Obviously with a small sample of 155 paired blood culture sets, the numbers of positive results and bacterial isolations obtained is of limited value, but a continuing trend of higher numbers of false positive

Table 2 Cumulative in vivo results

\begin{tabular}{|c|c|c|c|}
\hline & $\begin{array}{l}\text { Trial } 2 \\
\text { No }(\%)\end{array}$ & $\begin{array}{l}\text { Trial } 3 \\
\text { No }(\%)\end{array}$ & $\begin{array}{l}\text { Trial } 4 \\
\text { No }(\%)\end{array}$ \\
\hline $\begin{array}{l}\text { Total No of infected sets (not } \\
\text { infective episodes) }\end{array}$ & 246 & 52 & 14 \\
\hline $\begin{array}{l}\text { Bactec NR-660 sets positive } \\
\text { Signal sets positive } \\
\text { Total No of isolates } \\
\text { Total No of isolates detected } \\
\text { by Bactec NR- } 660\end{array}$ & $\begin{array}{l}231(93.9) \\
198(80.5) \\
301 \\
281(93.4)\end{array}$ & $\begin{array}{l}49(94 \cdot 2) \\
44(84 \cdot 6) \\
61 \\
56(91 \cdot 8)\end{array}$ & $\begin{array}{l}14(100) \\
10(71 \cdot 4) \\
15 \\
15(100)\end{array}$ \\
\hline $\begin{array}{l}\text { Total No of isolates detected } \\
\text { by Signal }\end{array}$ & $229(76 \cdot 1)$ & $49(80 \cdot 3)$ & $11(72 \cdot 0)$ \\
\hline
\end{tabular}

*This also excludes contaminants such as coagulase negative staphylococci or coryneforms isolated from only one bottle. 
Table 3 Comparison of in vivo detection times for Bactec NR-660 and Signal systems

\begin{tabular}{llccccc}
\hline \multicolumn{7}{l}{ No (\%) of isolates detected by system } \\
\cline { 2 - 7 } & \multicolumn{7}{l}{ Trial 2 } & \multicolumn{1}{l}{ Trial 3 } \\
\cline { 2 - 7 } & Bactec & Signal & Bactec & Signal & Bactec & Signal \\
\hline Early (less than 16 & $21(7 \cdot 5)$ & $4(1 \cdot 7)$ & $1(1 \cdot 8)$ & $1(2 \cdot 0)$ & $1(6 \cdot 7)$ & $6(9 \cdot 1)$ \\
hours) & $144(51 \cdot 3)$ & $69(30 \cdot 1)$ & $33(58 \cdot 9)$ & $25(51 \cdot 0)$ & $7(46 \cdot 7)$ & $6(54 \cdot 5)$ \\
AM 24 hours & $43(15 \cdot 3)$ & $45(19 \cdot 7)$ & $8(14 \cdot 3)$ & $5(10 \cdot 2)$ & 0 & $1(9 \cdot 1)$ \\
PM 24 hours & $56(19 \cdot 9)$ & $67(29 \cdot 3)$ & $7(12 \cdot 5)$ & $14(28 \cdot 6)$ & $5(33 \cdot 3)$ & $2(18 \cdot 2)$ \\
48 hours & $10(3 \cdot 6)$ & $18(7 \cdot 9)$ & $1(1 \cdot 8)$ & 0 & $1(9 \cdot 1)$ \\
Day 3 & $3(1 \cdot 1)$ & $20(8 \cdot 7)$ & $4(7 \cdot 1)$ & $2(4 \cdot 1)$ & 0 & 0 \\
Day 5 & $4(1 \cdot 4)$ & $6(2 \cdot 6)$ & $2(3 \cdot 6)$ & $2(4 \cdot 1)$ & $2(13 \cdot 3)$ & 0 \\
Day 7 & $281(93 \cdot 4)$ & $229(76 \cdot 1)$ & $56(91 \cdot 8)$ & $49(80 \cdot 3)$ & $15(100)$ & $11(72 \cdot 0)$ \\
& & &
\end{tabular}

results with Signal (13.5\%) compared with Bactec $(3.9 \%)$ was found.

\section{Discussion}

Bactec NR-660 is a technologically advanced detection system which requires considerable capital outlay with associated maintenance and running costs. Signal, a manual method, requires only visual inspection and no capital costs.

The in vivo trial was designed to determine the sensitivity of each system under controlled conditions. Although artificial, as bacteria were not subject to targeting from antibiotics or host defence mechanisms, the absolute time to detection can be established from the moment of inoculation.

Analysis of findings for major bacterial groups (table 1) in simulated blood cultures showed a highly significant difference $(p<0.001)$ between mean detection times for the Bactec NR-6A phial and any other under test. Comparable detection times were shown only for the isolation of members of Enterobacteriaceae.

The Signal system is designed for $0.1 \mathrm{ml}-10 \mathrm{ml}$ volumes (unlike Bactec NR-660 phials which require the addition of $3 \mathrm{ml}-5 \mathrm{ml}$ ) of drawn blood, which means that it can be used in children's hospitals. A disturbing feature, however, was the apparent delay in detection of the fastidious aerobic pathogens Haemophilus and Neisseria; Signal was 61 hours slower than Bactec NR-6A. This finding was further substantiated in trial 2 where Signal failed to isolate three strains of Haemophilus influenzae and two Neisseria sp. Therefore, children's hospitals should recommend that clinicians use blood volumes well in excess of $0 \cdot 1$ $\mathrm{ml}$ whenever possible.

Results from trial 2 showed that Signal failed to isolate $15.9 \%$ of Gram positive, $27.0 \%$ of Gram negative, but only $8.3 \%$ of anaerobic bacteria. Although there were only 12 anaerobic isolates, probably due to the use of metronidazole within the hospital, Signal produced a positive culture before Bactec NR-660.

Results from trial 3, using partially evacuated blood culture phials, continuous shaking for 24 hours, and improved manometer volumes, did improve isolation rates within the first 24 hours to $63.2 \%$ for Signal. Staff time is wasted, however, because of the need to deal with the increased numbers of false positive results generated by Signal under these conditions.

The media modification used in trial 4 did not correct the problem of false positive cultures, but increased them slightly. Both systems isolated $53.3 \%$ of all bacteria within 24 hours. A recent report (Roberts and Kaczmarski) $^{4}$ also commented on the numbers of false positive results and isolation failures of the Signal system.

In conclusion, the in vitro study of 99 bacteria in simulated blood cultures showed a highly significant difference $(p<0.001)$ in recovery rates for all bacteria between Bactec NR-6A and any other phial under test. The results of the prospective trial of 2000 paired patient samples also showed highly significant differences between the Bactec NR-660 and Signal for both absolute numbers of bacteria isolated and speed of detection. Improved aeration through shaking did improve isolation rates for Signal but increased the number of false positive cultures. Under these conditions Signal was not comparable with Bactec NR-660.

\section{References}

1 Corkill JE, Rimmer K. Microbiological comparison of a new infra-red blood culture system (Bactec NR-660) and a radiometric system (Bactec 460). Med Lab Sci 1987;44:150-9.

2 Strike PW. Medical laboratory statistics. Bristol: PG Wright, 1981.

3 Swinscow TDV. Statistics at square one. London: British Medical Association, 1983.

4 Roberts G, Kaczmarski E. Oxoid Signal blood culture system. $J$ Clin Pathol 1987;40:813.

Requests for reprints to: K Rimmer, Department of Medical Microbiology, Royal Liverpool Hospital, Prescot Street, Liverpool L7 8XP, England. 